\title{
ICP-OES Determination of Palladium in Palladium Jewellery Alloys Using Yttrium Internal Standard
}

\author{
Ruifeng Gao ${ }^{\mathrm{a}, \mathrm{b}}$ and Ning Zhang ${ }^{\mathrm{a} *}$ \\ a School of Physics and Technology, Nanjing Normal University, Nanjing 210023, P.R. China \\ b Nanjing Institute of Product Quality Inspection, Nanjing 210019, P.R. China
}

\section{INTRODUCTION}

Methods for measuring the palladium (Pd) concentrations in palladium jewellery alloys (1) generally include the gravimetric method with dimethylglyoxime $(2,3)$, complexometric titration (4), inductively coupled plasma optical emission spectroscopy (ICP-OES), internal standardization (5), and the difference method (6). Using internal standardization (7-11) of ICP-OES can improve precision, reduce matrix effects and drift. The direct determination of palladium by internal standardization with ICPOES (5) is feasible for routine applications, requires no tedious filtration separation, and is accurate, simple, and fast.

The ISO 11495:2008 regulation (5) recommends measuring the ratio of the intensity of $\mathrm{Pd}$ at 340.45 $\mathrm{nm}$ to the intensity of yttrium (Y) at $371.03 \mathrm{~nm}$, and using this ratio to calculate the concentration. The analytical line pair of Pd 342.124 $\mathrm{nm}$ vs. Y $371.030 \mathrm{~nm}$ is more commonly used for the determination of Pd (12). However, Pd at 340.45 $\mathrm{nm}$ is not available on an IRIS Intrepid II emission spectrometer. The charge-injection device detector of the spectrometer is CID38 (13) (Thermo CIDTEC, Liverpool, NY, USA) with a $512 \times 512$ array. Less than 10 or greater than 502 are in the edge of the array, which is an area that does not permit spectral analysis. The Pd 340.45-nm line, located in $(4.30,154.40)$ of the

\footnotetext{
* Corresponding author.

E-mail: zhangning@njnu.edu.cn
}

\begin{abstract}
A different analytical line pair is required when the Pd 340.45$\mathrm{nm}$ line, as recommended by ISO regulation 11495:2008, is not available on an inductively coupled plasma optical emission spectrometer (ICP-OES) for the determination of $\mathrm{Pd}$ in palladium jewellery alloys. This work selected Pd 342.124 $\mathrm{nm}$ and $\mathrm{Y}$ $371.030 \mathrm{~nm}$ as the optimal analytical line pair from 21 spectral lines of palladium and 7 spectral lines of yttrium based on recoveries, relative standard deviations (RSD), spectral interferences, simultaneous detection principle of the analyte and the internal standard signals. The recoveries of the line pair were in the range of $101.6 \sim 101.9 \%$ and the RSD was $0.2 \%(n=10)$. This method is complementary to the ISO 11495:2008 regulation.
\end{abstract}

array is just in the edge. Consequently, a new analytical line pair needs to be selected.
The aim of this work was to compare 147 analytical line pairs, composed of 21 spectral lines of palladium and 7 spectral lines of yttrium, and to select the optimal pair for the ICP-OES determination of Pd in palladium jewellery alloys.

\section{EXPERIMENTAL}

\section{Instrumentation}

The ICP-OES measurements were carried out using a radial IRIS Intrepid II XSP (Thermo Fisher Scientific, USA) with Echelle optics and a charge injection device (CID) detector for the simultaneous recording of the selected emission lines. The sample introduction system consisted of a cyclonic spray chamber and a Meinhard ${ }^{\circledR}$ concentric nebulizer. The system is controlled with TEVA ${ }^{\mathrm{TM}}$ software (Thermo Fisher Scientific, USA).

Table I lists the instrumental operating parameters. The chosen settings fulfill the robust plasma conditions (14) checked by the $\mathrm{Mg}(\mathrm{II}) / \mathrm{Mg}$ (I) ratio.

TABLE I

ICP-OES Instrumental Operating Parameters

\begin{tabular}{lc}
\hline Instrument & IRIS Intrepid II XSP ICP-OES \\
\hline RF power & $1150 \mathrm{~W}$ \\
Ar nebulizer gas pressure & $179 \mathrm{kPa}$ \\
Ar plasma gas flow rate & $15 \mathrm{~L} \mathrm{~min}^{-1}$ \\
Ar auxiliary gas flow rate & $1.0 \mathrm{~L} \mathrm{~min}^{-1}$ \\
Solution uptake rate & $2.40 \mathrm{~mL} \mathrm{~min}^{-1}$ \\
Maximum integration times & \\
(low wavelength range) & $30 \mathrm{~s}$ \\
Maximum integration times & \\
(high wavelength range) & $30 \mathrm{~s}$ \\
\hline
\end{tabular}




\section{Reagents and Samples}

Pd and Y reference solutions used for calibration were prepared by diluting a stock solution of 1000 $\mathrm{mg} \mathrm{L}^{-1}$ of the given element (supplied by the National Analysis Center for Iron and Steel of China) and stored in polyethylene bottles. $\mathrm{HCl}$ and $\mathrm{HNO}_{3}$ solutions were of analytical reagent grade. Deionized water with a specific resistivity of $\mathbf{1 8 . 2}$ $\mathrm{M} \Omega \cdot \mathrm{cm}$ (Milli-Q ${ }^{\circledR}$ gradient A10, Millipore Corporation, Bedford, MA, USA) was used to prepare the samples and standards.

Approximately $100 \mathrm{mg}$ of palladium jewelry alloy (Pd950) with a palladium content of $95 \%$ was weighed to at least $0.01 \mathrm{mg}$ and dissolved in $40 \mathrm{~mL}$ aqua regia in a $100-\mathrm{mL}$ volumetric flask. Then, $5 \mathrm{~mL}$ of the solution was placed into a $50-\mathrm{mL}$ volumetric flask, brought to volume with deionized water, and mixed thoroughly. A $1 \mathrm{mg} \mathrm{L}^{-1}$ amount of yttrium solution was used as the internal standard solution. The sample and internal standard solutions were mixed online.

\section{RESULTS AND DISCUSSION}

\section{Available Spectral Lines of Pd and $Y$}

The available 21 spectral lines of palladium and 20 spectral lines of yttrium are listed in Tables II and III, arranged by signal-to-background ratio (SBR). The net signal was the spectral line intensity of a single element of $10 \mathrm{mg} \mathrm{L}^{-1}$ after background subtraction. The diffraction order is listed in braces.

\section{Analytical Line Pairs}

Twenty-one spectral lines of Pd in Table II and seven strong spectral lines of $\mathrm{Y}$ in Table III were used in this research project. They compose 147 analytical line pairs. Among them, the wavelengths of $\mathrm{Y}$ at $324.228 \mathrm{~nm}$ and $\mathrm{Pd}$ at 324.270 $\mathrm{nm}$ are too close to each other, and the backgrounds need to be subtracted.

Using the 147 line pairs, the recovery and relative standard deviation (RSD) values for 10 replicate determinations from the palladium solution of $95 \mathrm{mg} \mathrm{L}^{-1}$ are shown in Figure 1. Table IV lists the 11 analytical line pairs which satisfies the following conditions: recoveries obtained between $95 \%$ and 105\% with an RSD of $<1.00 \%$. The 11 line pairs in Table IV are composed of 9 Pd spectral lines and $3 \mathrm{Y}$ spectral lines, arranged by recovery.

\section{TABLE II} 21 Spectral Lines of Pd

\begin{tabular}{|c|c|c|}
\hline Wavelength (nm) & Net Signal & SBR \\
\hline $\operatorname{Pd} 229.651\{146\}$ & 16.48 & 2.19 \\
\hline $\operatorname{Pd} 363.470\{92\}$ & 67.37 & 1.85 \\
\hline $\operatorname{Pd} 351.694\{95\}$ & 24.60 & 1.05 \\
\hline $\operatorname{Pd} 223.159\{151\}$ & 6.52 & 1.03 \\
\hline $\operatorname{Pd} 223.159\{150\}$ & 4.03 & 0.90 \\
\hline $\operatorname{Pd} 324.270\{103\}$ & 11.37 & 0.88 \\
\hline $\operatorname{Pd} 248.892\{134\}$ & 0.85 & 0.82 \\
\hline $\operatorname{Pd} 360.955\{93\}$ & 31.14 & 0.71 \\
\hline $\operatorname{Pd} 342.124\{98\}$ & 18.49 & 0.59 \\
\hline $\operatorname{Pd} 248.892\{135\}$ & 0.86 & 0.54 \\
\hline $\operatorname{Pd} 244.618\{137\}$ & 0.91 & 0.43 \\
\hline $\operatorname{Pd} 355.308\{94\}$ & 8.27 & 0.35 \\
\hline $\operatorname{Pd} 348.115\{96\}$ & 7.64 & 0.35 \\
\hline $\operatorname{Pd} 346.077\{97\}$ & 11.16 & 0.32 \\
\hline $\operatorname{Pd} 248.653\{135\}$ & 0.63 & 0.30 \\
\hline $\operatorname{Pd} 244.791\{137\}$ & 0.53 & 0.29 \\
\hline $\operatorname{Pd} 236.796\{141\}$ & 0.30 & 0.24 \\
\hline $\operatorname{Pd} 247.642\{135\}$ & 0.40 & 0.23 \\
\hline $\operatorname{Pd} 235.134\{142\}$ & 0.16 & 0.14 \\
\hline $\operatorname{Pd} 276.309\{121\}$ & 0.58 & 0.11 \\
\hline $\operatorname{Pd} 330.213\{102\}$ & 1.48 & 0.10 \\
\hline
\end{tabular}

\section{Seven Analytical Line Pairs}

The IRIS emission spectrometer uses a low wavelength slit and a high wavelength slit around the 234-nm line, respectively. There are four line pairs in Table IV (in bold font) on the use of the two slits; their analytical line and internal standard line were not determined simultaneously. The four line pairs were Pd $223.159 \mathrm{~nm}$ $\{151\}$ vs. Y $371.030 \mathrm{~nm}\{90\}, \mathrm{Pd}$ $223.159 \mathrm{~nm}\{150\}$ vs. Y 437.494 Y $361.105 \mathrm{~nm}\{93\}$, and Pd 223.159 $\mathrm{nm}\{150\}$ vs. Y $371.030 \mathrm{~nm}\{90\}$. Except for these four line pairs, the remaining seven line pairs are as follows: Y $371.030 \mathrm{~nm}\{90\}$ and

TABLE III 20 Spectral Lines of $Y$

\begin{tabular}{|c|c|c|}
\hline Wavelength $(\mathrm{nm})$ & Net Signal & SBR \\
\hline Y $324.228\{103\}$ & 483.1 & 50.32 \\
\hline Y $371.030\{90\}$ & 1320 & 49.58 \\
\hline Y $224.306\{150\}$ & 351.8 & 45.28 \\
\hline Y $360.073\{93\}$ & 1362 & 27.00 \\
\hline Y $377.433\{89\}$ & 1590 & 23.01 \\
\hline Y 361.105 \{93\} & 793.2 & 20.15 \\
\hline Y 437.494\{ 77\} & 1177 & 16.34 \\
\hline Y $320.332\{105\}$ & 164.7 & 13.81 \\
\hline Y $319.562\{105\}$ & 187.2 & 12.86 \\
\hline Y $320.027\{105\}$ & 163.5 & 11.05 \\
\hline Y $242.220\{138\}$ & 13.76 & 10.35 \\
\hline Y $358.452\{94\}$ & 166.6 & 9.43 \\
\hline Y $349.609\{96\}$ & 144.3 & 5.86 \\
\hline Y $488.369\{69\}$ & 1025 & 5.82 \\
\hline Y 423.594\{ 79\} & 269.5 & 3.55 \\
\hline Y $508.742\{66\}$ & 794.0 & 3.50 \\
\hline Y $485.487\{69\}$ & 460.2 & 2.47 \\
\hline Y $360.192\{93\}$ & 44.92 & 1.61 \\
\hline Y $439.802\{76\}$ & 34.40 & 0.34 \\
\hline Y 408.371\{82\} & 2.19 & 0.05 \\
\hline
\end{tabular}


seven spectral lines (in regular font) of Pd [276.309 $\mathrm{nm}\{121\}, 324.270$ $\mathrm{nm}\{103\}, 330.213 \mathrm{~nm}\{102\}$, $342.124 \mathrm{~nm}\{98\}, 348.115 \mathrm{~nm}\{96\}$, $351.694 \mathrm{~nm}\{95\}$, and $360.955 \mathrm{~nm}$ $\{93\}]$. The ionization and excitation energies of the seven line pairs are shown in bold font in Table $\mathrm{V}$.

Of the seven line pairs, $\mathrm{Pd}$ $330.213 \mathrm{~nm}\{102\}$ vs. Y $371.030 \mathrm{~nm}$ $\{90\}$ and $\mathrm{Pd} 342.124 \mathrm{~nm}\{98\}$ vs. Y $371.030 \mathrm{~nm}\{90\}$ were the line pairs with recoveries closest to $100 \%$ and of smaller \%RSD values.

\section{Spectral Interference}

Palladium jewellery alloys, in addition to Pd and Y, may also contain elements such as $\mathrm{Cu}, \mathrm{Ni}, \mathrm{Zn}$, $\mathrm{Fe}, \mathrm{Co}, \mathrm{Ru}, \mathrm{Ag}$, In, Ga, and Sn (2, 5, 15). The sum of any other trace elements present never exceeds $0.1 \%$ (15). The spectral interference of the nine spectral lines of Pd in Table IV with these elements was determined and found to be as follows: Pd $95 \mathrm{mg} \mathrm{L}^{-1}, \mathrm{Cu} 5 \mathrm{mg} \mathrm{L}^{-1}$, Ni $5 \mathrm{mg} \mathrm{L}^{-1}$, Zn $5 \mathrm{mg} \mathrm{L}^{-1}$, Fe $5 \mathrm{mg} \mathrm{L}^{-1}$, Co $5 \mathrm{mg} \mathrm{L}^{-1}$, Ru $5 \mathrm{mg} \mathrm{L}^{-1}$, Ag $5 \mathrm{mg} \mathrm{L}^{-1}$, In $10 \mathrm{mg} \mathrm{L}^{-1}$, Ga $5 \mathrm{mg} \mathrm{L}^{-1}$, Sn $5 \mathrm{mg} \mathrm{L}^{-1}$, and $\mathrm{Y} 10 \mathrm{mg} \mathrm{L}^{-1}$. The presence of $\mathrm{Zn}$ at the 330.259-nm line to the left of Pd at $330.213 \mathrm{~nm}$ is shown in Figure 2. All other lines showed no interference.

\section{Optimal Analytical Line Pair}

The optimal analytical line pair of the 147 line pairs was $\mathrm{Pd}$ $342.124\{98\}$ vs. Y $371.030\{90\}$, based on the evaluation of the recoveries, RSD values, spectral interferences, and simultaneous detection principle of the analyte and the internal standard signals.

The ionization and excitation energies (16) of the spectral lines as listed in Table $\mathrm{V}$ are arranged according to excitation energy. The letters I and II represent the atomic and ionic lines, respectively.

\section{Analytical Line Pairs* (Arranged by Recovery)}

\begin{tabular}{|c|c|c|c|}
\hline $\begin{array}{l}\text { Analytical Line } \\
\text { (nm) }\end{array}$ & $\begin{array}{c}\text { Internal Standard } \\
\text { Line }(\mathrm{nm})\end{array}$ & $\begin{array}{c}\text { Recovery } \\
(\%)\end{array}$ & $\begin{array}{l}\text { RSD } \\
(\%)\end{array}$ \\
\hline Pd 223.159 $\{151\}$ & Y 371.030 $\{90\}$ & 95.1 & 0.80 \\
\hline Pd 223.159 $\{150\}$ & Y 437.494 $\{77\}$ & 95.8 & 0.92 \\
\hline $\operatorname{Pd} 324.270\{103\}$ & Y $371.030\{90\}$ & 96.7 & 0.80 \\
\hline $\operatorname{Pd} 351.694\{95\}$ & Y $371.030\{90\}$ & 97.0 & 0.92 \\
\hline $\operatorname{Pd} 348.115\{96\}$ & Y $371.030\{90\}$ & 97.3 & 0.97 \\
\hline $\operatorname{Pd} 360.955\{93\}$ & Y $371.030\{90\}$ & 98.2 & 0.92 \\
\hline Pd 223.159 $\{150\}$ & Y 361.105 $\{93\}$ & 98.5 & 1.00 \\
\hline $\operatorname{Pd} 330.213\{102\}$ & Y $371.030\{90\}$ & 99.1 & 0.91 \\
\hline $\operatorname{Pd} 342.124\{98\}$ & Y $371.030\{90\}$ & 101.7 & 0.88 \\
\hline $\operatorname{Pd} 276.309\{121\}$ & Y $371.030\{90\}$ & 102.3 & 0.92 \\
\hline Pd 223.159 $\{150\}$ & Y $371.030\{90\}$ & 102.4 & 0.84 \\
\hline
\end{tabular}

*: The four line pairs are shown in bold font, which are exposed non-simultaneously from the two different slits.

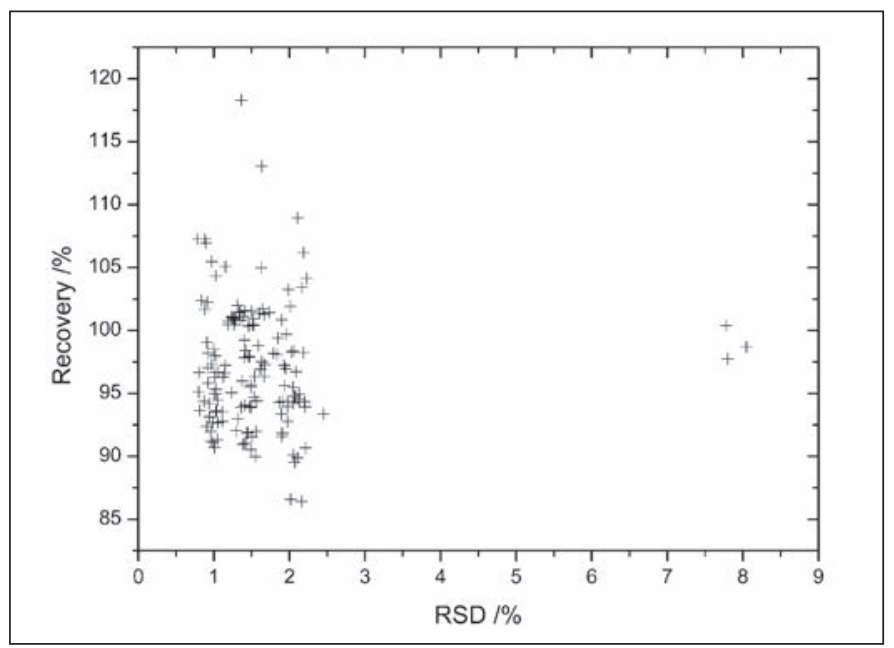

Fig. 1. Recoveries and RSDs of 147 analytical line pairs.

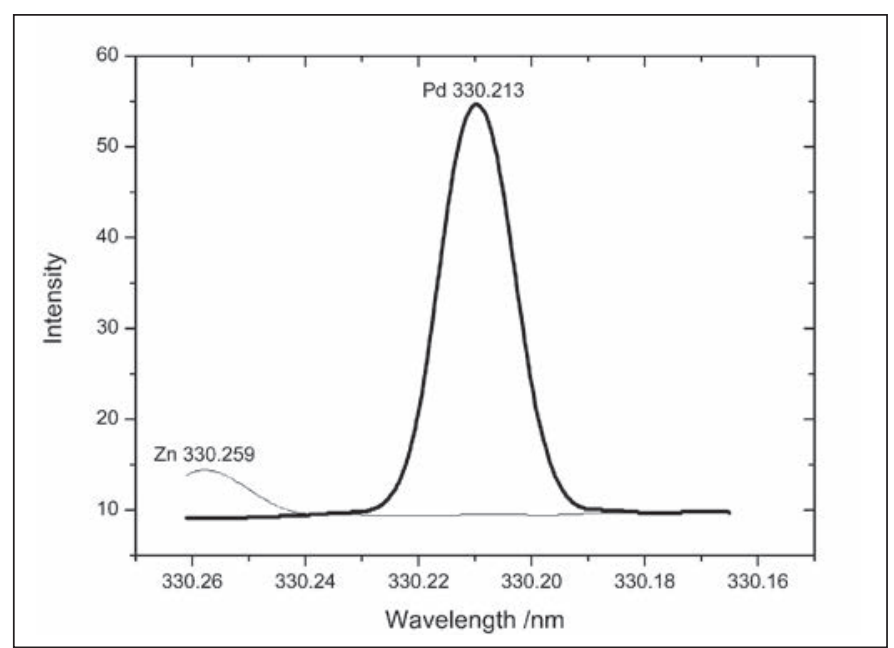

Fig.2. Spectral coincidence profiles of Pd at $330.213 \mathrm{~nm}$ (95 $\left.\mathrm{mg} \mathrm{L}^{-1}\right)$ and $\mathrm{Zn}$ at $330.259 \mathrm{~nm}\left(5 \mathrm{mg} \mathrm{L}^{-1}\right)$. 


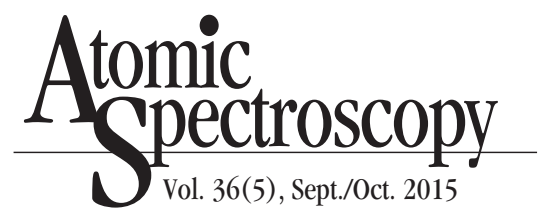

TABLE V

Ionization and Excitation Energies of Spectral Lines*

\begin{tabular}{|c|c|c|c|c|c|}
\hline $\begin{array}{l}\text { Wavelength } \\
\text { (nm) }\end{array}$ & $\begin{array}{l}\text { Atomic/ } \\
\text { Ionic }\end{array}$ & $\begin{array}{l}\text { Ionization } \\
\text { Energy eV) }\end{array}$ & $\begin{array}{c}\text { Excitation } \\
\text { Energy }(\mathrm{eV})\end{array}$ & $\begin{array}{c}\text { Energy } \\
\text { Sum (eV) (a }\end{array}$ & $\begin{array}{c}\text { SBR } \\
\left.10 \mathrm{mg} \mathrm{L}^{-1}\right)\end{array}$ \\
\hline Y $437.494\{77\}$ & II & 6.22 & 3.24 & 9.46 & 16.34 \\
\hline Y $377.433\{89\}$ & II & 6.22 & 3.41 & 9.63 & 23.01 \\
\hline Y $371.030\{90\}$ & II & 6.22 & 3.52 & 9.74 & 49.58 \\
\hline Y $361.105\{93\}$ & II & 6.22 & 3.56 & 9.78 & 20.15 \\
\hline Y $360.073\{93\}$ & II & 6.22 & 3.62 & 9.84 & 27.00 \\
\hline Y $324.228\{103\}$ & II & 6.22 & 4.00 & 10.22 & 50.32 \\
\hline $\operatorname{Pd} 363.470\{92\}$ & I & & 4.22 & 4.22 & 1.85 \\
\hline Pd $346.077\{97\}$ & I & & 4.40 & 4.40 & 0.32 \\
\hline Pd $360.955\{93\}$ & I & & 4.40 & 4.40 & 0.71 \\
\hline Pd 276.309 $\{121\}$ & I & & 4.49 & 4.49 & 0.11 \\
\hline Pd 351.694 \{95\} & I & & 4.49 & 4.49 & 1.05 \\
\hline Pd $342.124\{98\}$ & $\mathbf{I}$ & & 4.58 & 4.58 & 0.59 \\
\hline Pd 324.270 $\{103\}$ & $\mathbf{I}$ & & 4.64 & 4.64 & 0.88 \\
\hline $\operatorname{Pd} 348.115\{96\}$ & I & & 4.81 & 4.81 & 0.35 \\
\hline $\operatorname{Pd} 355.308\{94\}$ & I & & 4.94 & 4.94 & 0.35 \\
\hline $\operatorname{Pd} 247.642\{135\}$ & I & & 5.01 & 5.01 & 0.23 \\
\hline $\operatorname{Pd} 330.213\{102\}$ & I & & 5.01 & 5.01 & 0.10 \\
\hline Pd $244.791\{137\}$ & I & & 5.06 & 5.06 & 0.29 \\
\hline Y $224.306\{150\}$ & II & 6.22 & 5.53 & 11.74 & 45.28 \\
\hline Pd $248.892\{134\}$ & II & 8.33 & 8.09 & 16.43 & 0.82 \\
\hline $\operatorname{Pd} 248.892\{135\}$ & II & 8.33 & 8.09 & 16.43 & 0.54 \\
\hline Pd $236.796\{141\}$ & II & 8.33 & 8.34 & 16.68 & 0.24 \\
\hline $\operatorname{Pd} 248.653\{135\}$ & II & 8.33 & 8.34 & 16.68 & 0.30 \\
\hline $\operatorname{Pd} 244.618\{137\}$ & II & 8.33 & 8.43 & 16.76 & 0.43 \\
\hline Pd $229.651\{146\}$ & II & 8.33 & 8.51 & 16.84 & 2.19 \\
\hline $\operatorname{Pd} 235.134\{142\}$ & II & 8.33 & 8.63 & 16.97 & 0.14 \\
\hline $\operatorname{Pd} 223.159\{150\}$ & II & 8.33 & 8.66 & 17.00 & 0.90 \\
\hline Pd $223.159\{151\}$ & II & 8.33 & 8.66 & 17.00 & 1.0 \\
\hline
\end{tabular}

*: The seven line pairs, composed by seven Pd spectral lines and one Y spectral line are shown in bold font, which satisfy the following conditions: recoveries obtained between $95 \%$ and $105 \%$, an RSD of $<1.00 \%$, and the simultaneous detection principle.
The data in Table $\mathrm{V}$ can be interpreted as follows:

(a) An analytical line pair is not necessarily a combination of two atomic lines or two ionic lines. The optimal analytical line pair in this paper consists of one atomic line and one ionic line. The line pair of Al I 396.153 nm vs. Y II 371.029 $\mathrm{nm}$ adopted by Roberta Eliane dos Santos Froes et al. (17) in their study is also a combination of one atomic line and one ionic line.

(b) To determine major elements, the best analytical line is often not the most sensitive line. The minimum SBR of the 21 spectral lines of Pd in Table $\mathrm{V}$ was 0.10 , maximum 2.19. The SBR of Pd $342.124 \mathrm{~nm}\{98\}$ was 0.59 , which was a weak line.

(c) Both the internal standard and the analytical lines should have similar excitation energies. The seven line pairs shown in bold font in Table $\mathrm{V}$ have closer excitation energies (3.52 eV, 4.40 5.01 eV); and their energy sum showed no regularity $(9.74 \mathrm{eV}, 4.40 \sim 5.01 \mathrm{eV})$.

(d) Accuracy and precision are the final screening indicators for the analytical line pair.

\section{Application to Commercial Pd950 Alloys}

The calibration curve was prepared with reference solutions of 50, 70, 80, 90 and $100 \mathrm{mg} \mathrm{L}^{-1} \mathrm{Pd}$. The linear regression equation was $\mathrm{Y}=-0.25021+0.12461^{*} \mathrm{X}$, where $\mathrm{X}$ was the concentration of Pd (mg $\mathrm{L}^{-1}$ ) and $\mathrm{Y}$ was the intensity ratio of the analytical line and the internal standard line. The correlation coefficient was 0.99976 . The precision of the method, expressed as \%RSD values for 10 replicate determinations from the palladium solution of $95 \mathrm{mg} \mathrm{L}^{-1}$, was $0.21 \%$. The accuracy of the method was verified by performing the recovery test. A $2-\mathrm{mL}$ sample solution of $\sim 950 \mathrm{mg} \mathrm{L}^{-1} \mathrm{Pd}$ was placed into a $50-\mathrm{mL}$ volumetric 
flask, then spiked with $2 \mathrm{mg}$ and $3 \mathrm{mg}$ of Pd, and made up to volume with $10 \%$ (v/v) HCl. The spike recoveries obtained were $101.6 \%$ and $101.9 \%$, respectively.

\section{CONCLUSION}

A new optimal analytical line pair (Pd $342.124 \mathrm{~nm}$ vs. Y 371.030 $\mathrm{nm}$ ) is recommended for the ICPOES determination of palladium in palladium jewellery alloys when Pd $340.45 \mathrm{~nm}$ is not available, as for instance, when using the radial IRIS Intrepid II XSP spectrometer. The recoveries of the new line pair were in the range of 101.6 101.9\%. The RSD was $0.2 \%(n=10)$. This method is complementary to the ISO 11495:2008 regulation.

\section{ACKNOWLEDGMENT}

The authors gratefully acknowledge the financial support for this work by the Jiangsu Planned Projects for Postdoctoral Research Funds (1202029C), the Key Technologies R\&D Program of Nanjing Bureau of Quality and Technical Supervision (kj2011014, kj2012010), and the Nanjing Institute of Product Quality Inspection.

Received January 3, 2015.

\section{REFERENCES}

1. ISO 9202 (1991), Jewellery Fineness of precious metal alloys.

2. ISO 11490 (1995), Determination of palladium in palladium jewellery alloys - Gravimetric determination with dimethylglyoxime.

3. GB/T 15072.4 (2008), P.R. China, Test method of precious metal alloys - Determination of palladium content for palladium and silver alloys - Butanedione dioxime gravimetry.

4. YS/T 372.3 (2006), P.R. China, Methods for elementary analysis of precious alloy - Determination of palladium content - Complexomet- ric titration using butanedione dioxime releasing EDTA.

5. ISO 11495 (2008), Jewellery - Determination of palladium in palladium jewellery alloys - Inductively coupled plasma (ICP) solution-spectrometric method using yttrium as internal standard element.

6. ISO 15093 (2008), Jewellery - Determination of precious metals in 999\% gold, platinum and palladium jewellery alloys - Difference method using inductively coupled plasma optical emission spectroscopy (ICP-OES).

7. W.B. Barnett, V.A. Fassel and R.N. Kniseley, Spectrochim. Acta Part B 23, 643 (1968).

8. J.C. Ivaldi and J.F. Tyson, Spectrochim. Acta Part B, 51, 1443 (1996).

9. K. Mitko and M. Bebek, At. Spectrosc. 21(3), 77 (2000).

10. W. Bussel, F. Kerkhof, T. Kessel, H. Lamers, D. Nous, H. Verdonk, B. Verhoeven, N. Boer and H. Toonen, At. Spectrosc.31(3), 81 (2010).

11. G.A. Zachariadis and C. Vogiatzis, Appl. Spectrosc. Reviews 45(3), 220 (2010).

12. N.S. Mokgalaka, R.I. McCrindle, B.M. Botha and L. Marjanovic, South African J. of Chem. 55, 72 (2002).

13. F.M. Pennebaker and M.B. Denton, Appl. Spectrosc. 55(6), 722 (2001).

14. J.M. Mermet, Anal. Chim. Acta 250, 85 (1991).

15. QB/T 4443 (2012), P.R. China, Composition of platinum \& palladium alloy adornments.

16. A. Kramida, Y. Ralchenko, J. Reader and NIST ASD Team (2013). NIST Atomic Spectra Database (ver. 5.1), [Online]. Available: http://physics.nist.gov/asd[2014, August 10], National Institute of Standards and Technology, Gaithersburg, MD, USA.

17. R.E.S. Froes, N.O.C. Silva, R.L.P. Naveira, J.C.J. Silva, V.S.T. Ciminelli, C.C. Windmöller and J.B.B. Silva, At. Spectrosc. 28(1), 8 (2007). 